\title{
DISTRIBUIÇÃO E TIPOLOGIA DAS OBRAS COSTEIRAS NO LITORAL FLUMINENSE
}

\author{
Laura Rangel Netto ${ }^{(a)}$, Eduardo Manuel Rosa Bulhões ${ }^{(b)}$ \\ (a)Departamento de Geografia de Campos, Universidade Federal Fluminense, laurarangel@id.uff.br

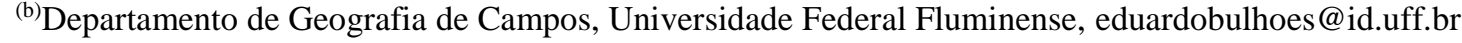

\section{Eixo: DINÂMICA E GESTÃO DE ZONAS COSTEIRAS}

\begin{abstract}
Resumo
O litoral Fluminense é caracterizado por abranger diversas obras sendo estas com diferentes finalidades. A proposta desse artigo é fazer um levantamento quantificando as obras costeiras existentes no litoral fluminense correspondente entre a foz do rio Itabapoana (ao norte) e a baía de Guanabara (a oeste), quanto a sua categoria, especificamente, as de defesa do litoral cuja função é intervir na ação erosiva e as de abrigo portuário em que a finalidade é oferecer proteção as embarcações nos portos agindo de forma que estes não sofram com a ação marítima e facilitando seu acesso e circulação. Através de interpretação de imagens de satélite e ortofotos e rotinas de geoprocessamento foi possível identificar que $50 \%$ das obras costeiras correspondem à categoria defesa do litoral, sobretudo na forma de obras longitudinais aderentes e que dentre as outras categorias a tipologia píer é a que mais se destaca.
\end{abstract}

Palavras chave: zona costeira, obras costeiras, categoria de obras

\section{Introdução}

Um dos principais desafios da gestão costeira é conciliar a preservação da biodiversidade existente junto aos fatores antrópicos e seu consequente uso do solo voltados aos interesses econômicos. Segundo Ab'Sáber (2003) o litoral do Brasil apresenta cerca de 8.000 quilômetros de extensão sendo considerado o maior litoral inter e subtropical do mundo. Essa imensa linha de costa é caracterizada por ser um ambiente que abriga diferentes aspectos paisagísticos e morfológicos atraentes a diversos interesses de exploração econômica como turismo, logística portuária, indústria, parques eólicos, dentre outros. Esses interesses ocorrem associados a uma intensa urbanização onde, conforme o IBGE (2011), 45,6\% dos municípios costeiros apresentam urbanização entre $80 \%$ e $100 \%$ e concentram 24,6\% da população. Em consequência dessa exposição que a costa se encontra, a dinâmica do litoral como também a vida dos ecossistemas presentes é comprometida podendo gerar graves problemas ambientais.

As obras costeiras são construções que estão ligadas diretamente às necessidades das atividades humanas podendo ter diferentes funções específicas e de acordo com Alfredini e Arasaki (2009) podem ser agrupadas em duas principais categorias: a) Obras de Defesa do Litoral e b) Obras de Abrigo Portuário. Diante disso, o objetivo geral deste trabalho é identificar as tipologias e classificar por categorias as obras costeiras ao longo do litoral fluminense, mais especificamente entre a foz do 
rio Itabapoana (ao norte) e a baía de Guanabara (a oeste) visando compor uma base de dados georreferenciados sobre a tipologia e os impactos das estruturas de engenharia costeira na morfologia do litoral.

\section{Pré-condições para determinar o projeto de obra}

Para um projeto de obra ser estabelecido é necessário considerar alguns aspectos que são primordiais. Segundo Alfredini e Arasaki (2009), um projeto de obra de defesa do litoral, por exemplo, é estabelecido de acordo com os aspectos básicos necessários que são o econômico ao que corresponde a relação custo-benefício, o ambiental que está associado as questões socioeconômicas, ecológicas e estética, e por último a segurança de que a obra influencie minimamente nas áreas ao redor evitando expor ou agravar processos erosivos existentes. Ademais é indispensável levar em consideração os parâmetros característicos do local correspondente aos aspectos meteorológicos e a circulação hidrodinâmica, sobretudo considerando estimativas para correntes costeiras, regime de marés, regime de ondas, direção e velocidade dos ventos, exposição da costa às tempestades, características das tempestades, além de estimativas de evolução da costa (geomorfologia) buscando estabelecer possíveis tendências do comportamento recente da linha de costa. De maneira geral, é preciso compreender os processos dinâmicos locais e regionais para que assim seja possível estimar primeiramente se o local é propício a receber determinada construção e, se caso for propício, estipular os possíveis resultados que a implementação de uma estrutura pode ocasionar no ambiente.

\section{Obras de defesa do litoral}

A erosão costeira é um fenômeno natural que, segundo Muehe (2003), uma das causas mais frequentes é a alteração no volume de sedimentos que são transportados paralelamente à linha de costa. $\mathrm{O}$ resultado dessa ação é a maior remoção dos sedimentos do que a deposição havendo então um desequilíbrio na dinâmica natural. Em virtude desse processo as obras de proteção costeira são estruturas que atuam no sentido de defender o litoral que, de acordo com Alfredini e Arasaki (2009), buscam intervir na erosão da costa, no balanço do transporte sólido e na estabilização ou ampliação da linha de costa. Pelo fato da zona costeira ser densamente ocupada, abrangendo infraestruturas urbanas e de desenvolvimento econômico, a erosão se torna um agravante, e por isso as obras ocorrem também visando o interesse em conter a erosão sobre as estruturas materiais construídas pelo homem, cujo fenômeno pode interferir na exploração econômica gerando perdas.

De acordo com Alfredini e Arasaki (2009) os tipos mais comuns de obras de defesa do litoral são espigões, quebra-mares, obras longitudinais aderentes (muros/paredões/enrocamento) e alimentação artificial de praias. Os espigões são construções transversais fixados na costa estendido do pós-praia até atingir a faixa de arrebentação atuando diretamente sobre o transporte de sedimentos litorâneo na 
zona em que ele é mais expressivo. Os espigões podem agir isoladamente ou em conjunto formando um campo de espigões. As funções desse tipo de estrutura é intervir parcialmente ou totalmente no transporte de sedimentos litorâneo fazendo com que ocorra deposição a barlamar, estabilizar praias sujeita a modificações, alargar a extensão das praias e evitar assoreamento a sotamar. Os quebra-mares são estruturas construídas distante e sem contato com a costa em posição paralela a esta podendo ser submerso ou não. Sua função é intervir sobre as ondas dissipando sua energia antes de alcançarem a praia reduzindo assim seu poder erosivo. As obras longitudinais aderentes são utilizadas para estabelecer o limite da praia em costas que não possuem proteção natural adequada. As funções dessas estruturas são resistir a ação de ondas desde fracas a severas e coibir inundações em ocorrência de eventos meteorológicos extremos. A alimentação artificial de praias consiste em abastecer artificialmente a faixa da costa estabilizando e ampliando praias sujeitas a erosão. Suas funções visam intervir no balanço sedimentar, reestabelecer o transporte sedimentar litorâneo e assumir característica de proteção.

\section{Obras de abrigo portuário}

O porto é uma estrutura de grande importância econômica sendo um dos principais meios de trocas comerciais entre os países. Segundo a Agência Nacional de Transporte Aquaviários (ANTAQ, 2009), porto corresponde a toda área que compreende as instalações portuárias tais como ancoradouros, docas, cais, pontes, píeres, terrenos, armazéns, edificações, vias de circulação interna, assim como a infraestrutura de proteção e acesso ao porto como guias-correntes, quebra-mares, eclusas, canais, bacias de evolução e áreas de fundeio. Tais estruturas de proteção são fundamentais para formar uma área de abrigo contra as ondas de gravidade geradas pelo vento ou por correntes garantindo uma área segura para a passagem e acostagem das embarcações.

As principais obras de abrigo portuário, segundo Alfredini e Arasaki (2009), são quebra-mares, molhes ou molhes guia-correntes e espigões. Os quebra-mares e molhes são estruturas que vão intervir diretamente na ação das ondas de gravidade geradas pelo vento agindo como um obstáculo, de modo que, estas percam sua energia propiciando assim uma área sem perturbações ondulatórias. Os molhes guias-correntes são estruturas transversais e paralelas entre si que dificultam a entrada da agitação marinha formando um canal de acesso facilitando assim as manobras de entrada e saída das embarcações. E por último os espigões que são estruturas posicionadas transversalmente a costa e vão proteger o porto de maneira a impedir a passagem das ondas geradas por correntes.

\section{Materiais e Métodos}

A execução do trabalho consistiu, primeiramente, na utilização do Google Earth Pro que permitiu marcar e identificar as obras localizadas dentro da área de estudo, além das ortofotos do Projeto RJ25 
do IBGE. Foram utilizados os programas Quantum GIS e ArcGIS para as edições e análises vetoriais incluindo a consolidação da tabela de atributos. Foi então possível classificar as obras por categorias (defesa do litoral, abrigo portuário e outros) e por tipologia (espigão, píer, obras aderentes, quebramar, etc). Dessa forma, foi possível elaborar o mapa de distribuição das obras de acordo com as categorias e tipologias estipuladas e gerar os gráficos através do MSExcel.

\section{Resultados}

Com os dados adquiridos foi possível apurar os primeiros resultados a partir da elaboração do mapa de distribuição das obras de acordo com sua categoria de abrigo portuário, defesa do litoral e outros (Figura 1) que conforme a análise, constata-se em maior presença as obras de defesa do litoral de Macaé até a baía de Guanabara, em Niterói, e a ausência desta ao norte do litoral, onde ocorre as obras de abrigo portuário. Há também em considerável quantidade a existência de outras obras que correspondem a tipologia de píer e passarela em todo recorte da área de estudo. Essas tipologias estão relacionadas a obras de acostagem de embarcações, como é o caso do píer, e de acessibilidade a praia que são as passarelas.

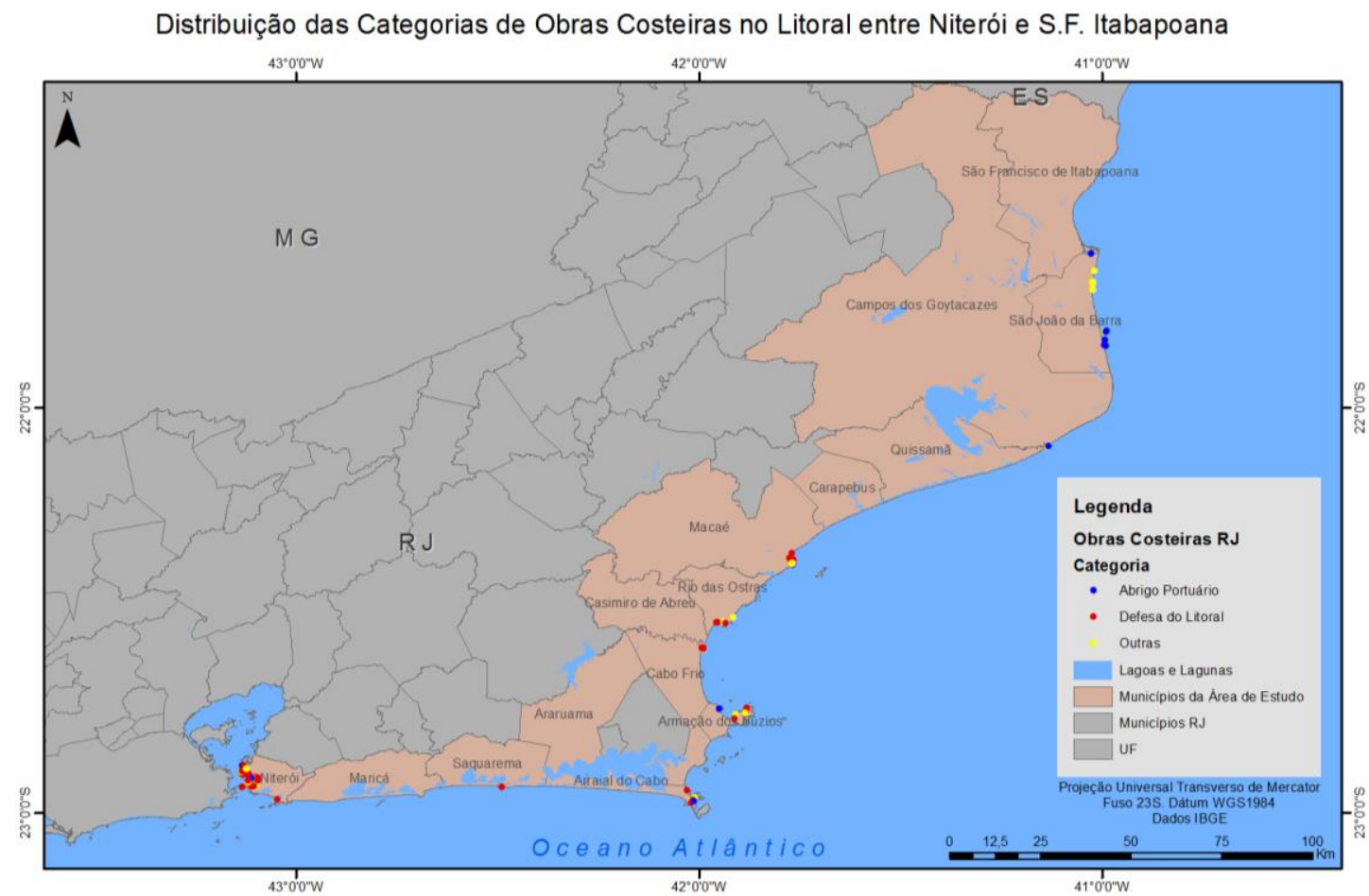

Figura 1 - Mapa de distribuição das obras costeiras

Além do mapa, foram elaborados também gráficos que atribuem valores percentuais pelas categorias e tipologias, em conformidade com o total de 153 obras identificadas, sendo: 77 defesa do litoral; 17 abrigo portuário; 59 outras. Das tipologias encontradas consta-se 54 píeres, 5 passarelas, 4 quebramares, 7 molhes, 10 guias-corrente, 65 obras longitudinais aderentes (muros e enrocamentos) e 8 espigões. De acordo com esses números, os gráficos a seguir dispõem do valor percentual correspondente a cada categoria (Figura 2) e a cada tipologia encontrada (Figura 3). 


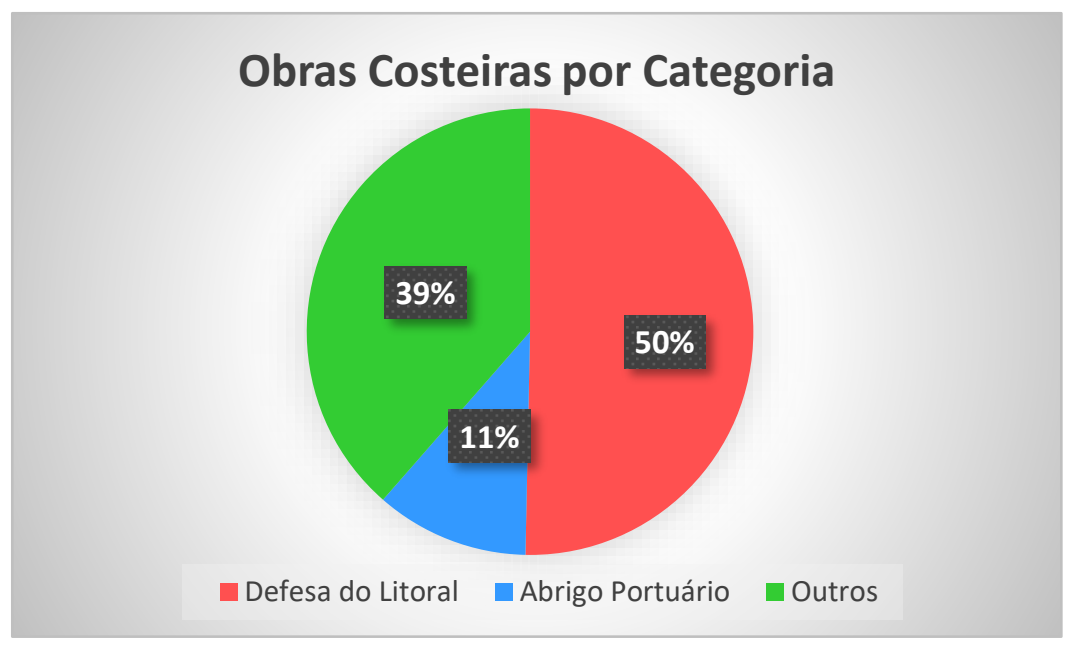

Figura 2 - Obras Costeiras por Categoria

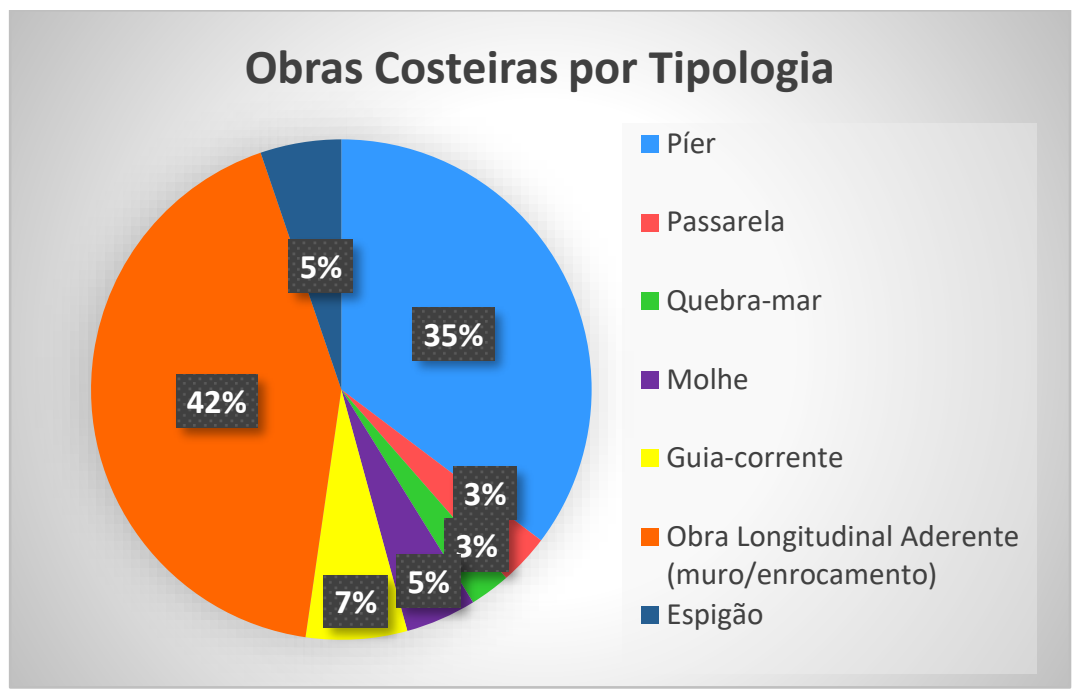

Figura 3 - Obras Costeiras por Tipologia

\section{Considerações Finais}

Baseado nos resultados iniciais aqui apontados, compreende-se que as obras dispostas dentro da área de estudo são em maior número de defesa do litoral (50\%) em virtude de proteger não só a faixa de praia, mas também as estruturas urbanas existentes, por isso encontram-se mais concentradas nos municípios onde a área urbana está inserida na faixa de costa. Em contraposição têm-se as obras de abrigo portuário que aparecem de maneira menos expressiva, concentradas em 4 portos ao longo da área de estudo. As próximas etapas do trabalho são estender a metodologia até o litoral sul fluminense e incorporar informações adicionais (dimensões, materiais e etc) à tabela de atributos.

\section{REFERÊNCIAS}

AB’SÁBER, N. A. Litoral do Brasil. $1^{\circ}$ Edição. São Paulo: Metalivros, 2003. 
Agência Nacional de Transporte Aquaviários. Disponível em: <http://www.antaq.gov.br/Portal/default.asp?> Acesso em: 10/02/2017.

ALFREDINI, P.; ARASAKI, E. Obras e gestão de portos e costas: A técnica aliada ao enfoque logístico e ambiental. $2^{\text {a }}$ Edição. São Paulo: Editora Blucher, 2009.

IBGE, Instituto Brasileiro de Geografia e Estatística. Atlas Geográfico das Zonas Costeiras e Oceânicas do Brasil. IBGE, Diretoria de Geociências, Rio de Janeiro, 176p. 2011.

MUEHE, D.O Litoral Brasileiro e sua Compartimentação. In: Guerra, A. J. T. \& Cunha, S.B. (org). Geomorfologia do Brasil. Cap. 7. Ed. Bertrand Brasil, 1998. pp. 273-349. 